in vivo $36: 1021-1029$ (2022)

doi:10.21873/invivo.12797

\title{
Sequential Loss of Mandibular Permanent Incisors in Noonan Syndrome
}

\author{
REINHARD E. FRIEDRICH ${ }^{1}$ and HANNA A. SCHEUER ${ }^{2}$ \\ ${ }^{1}$ Department of Oral and Craniomaxillofacial Surgery, \\ Eppendorf University Hospital, University of Hamburg, Hamburg, Germany; \\ ${ }^{2}$ Department of Orthodontics, Eppendorf University Hospital, University of Hamburg, Hamburg, Germany
}

\begin{abstract}
Background: Noonan syndrome (NS) is a multigenic disorder with a highly variable phenotype. Cardiac disorders and a predisposition to neoplasm often require early medical attention. Central giant central lesions (CGCLs) of the jaws are part of the phenotype. Case Report: In a patient with genetically confirmed NS and multiple teeth loss presumably caused by CGCL, careful review of the medical history and radiographic findings made it probable that the cause of tooth loss was cervical root resorption (CRR) of the teeth following long-term orthodontic therapy. Conclusion: CRR is a rare dental disease of unknown origin. However, association with prior orthodontic therapy is well documented. In NS, mandibular lesions can occur which, at first glance, might lead the examiner to assume that it is a CGCL, but on closer analysis, obviously are of non-tumorous origin and should be assessed as coincidental. The report adds relevant information to orthodontic treatment of NS patients.
\end{abstract}

Noonan syndrome (NS) is a rare, multisystemic disorder characterized by short stature, heart diseases (e.g., congenital heart defects, cardiomyopathy), and an increased risk of developing tumors in childhood (1). Typical facial dysmorphia such as frontal bossing or open bite may be recorded in affected individuals (2). However, the phenotype is highly variable, therefore diagnosis often must be made late in oligosymptomatic cases (3).

This article is freely accessible online.

Correspondence to: Prof. Reinhard E. Friedrich, MD, DMD, Ph.D., FEBOMFS, Department of Oral and Craniomaxillofacial Surgery, Eppendorf University Hospital, University of Hamburg, 20246 Hamburg, Germany. Tel: +49 40741053259, e-mail: rfriedrich@uke.de

Key Words: Noonan syndrome, cervical root resorption, invasive lateral root resorption, central giant cell granuloma, orthodontics.
Bone changes belong to the spectrum of NS (2). Central giant cell lesions (CGCLs) of the jaws are diagnosed in some cases and may need to be treated. However, CGCL is not a characteristic feature of NS, because numerous inherited diseases can develop the jaw lesions and share a common genetic basis with sporadic CGCL (4). Indeed, it has been shown that in both sporadic and syndromic CGCL of the jaws, mutations occur in genes that control essential functions in the rat sarcoma (RAS) pathway (5).

Thus, local destruction of the jaw, possibly associated with tooth loss, is an important clinical finding in the case of known NS (6-10). Diagnosis of such jaw lesions in NS must consider CGCL (11-22). However, other jaw diseases in NS can have some aspects of CGCL $(23,24)$. The following report is intended to add further oral lesions to the spectrum of findings in NS.

\section{Case Report}

Reason for current investigation. The 17-year-old female patient presented to the outpatient clinic of the University Clinic of Oral and Craniomaxillofacial Surgery for a consultative examination following the morbid event of protracted, multiple teeth loss of the anterior lower jaw some years ago. The patient had a known NS. The patient's presentation was requested by the local treating physicians to determine whether a syndrome related to CGCL of the anterior mandible had caused tooth and bone loss. Furthermore, assessment was required whether tooth replacement by insertion of implants would increase the risk of a new bone lesion due to the known genetic background of the patient. The previous course of the disease had to be assessed from radiological pictures of the jaws (Figure 1, Figure 2 and Figure 3).

Medical history. At the age of 2 years, pulmonary valve commissurotomy had been performed. At present, moderate pulmonary and mitral valve insufficiency allow normal physical activity excluding competitive sports. At the time 
of initial tooth loss, paediatric examination had revealed suspicious facies, anti-mongoloid eye axes, long face, bitemporal impressions, hypertelorism, slim hands, and no skin marks. A considered general metabolic disorder as cause of the tooth loss was excluded. Alternatively, a syndrome was suspected causing the local bone disease. Clinical findings were assessed as indicating cardio-facio-cutaneous or NS and recommended genetic testing. After the patient's NS was confirmed by genetic analysis, the parents and her sister were also tested for the pathogenic mutation. The patient's medical files showed that the index patient, the biological sister, and their common mother all are affected by the same mutation (mutation in RIT1 gene: c.284>C; p.G95A). In this case, abnormal tooth loss had led to extended medical diagnosis and maternally transmitted RASopathy was identified in the patient at the age of 14 years. The disease of teeth and bone was retrospectively interpreted as CGCL because of the known association of NS with jaw lesions. On admission, body height and weight did not differ from expected normal range $(172 \mathrm{~cm}, 79.9 \mathrm{~kg})$.

The patient had been in orthodontic therapy since her $9^{\text {th }}$ year lasting up to the period of successive tooth losses starting at the age of 13 years. The patient reported to have noticed first loosening of one inferior front tooth. The patient described an onset of tooth loosening with loss of subcoronal tooth structure. Granulomatous changes in the adjacent mucosa were not noted. Over an interval of about three years, the patient lost one by one all four inferior incisors following the same pattern of initially subcoronal tooth destruction (Figure 1A-D, Figure 2 and Figure 3). The orthodontic therapy stopped immediately after the first diagnosis of a dissolving tooth and the inferior incisors were interdentally connected to each other with an arch wire splint that was fixed with acid-etch fixation only on the inferior incisors. This splint held the remaining tooth crown after root loss in the tooth row (Figure 1B-D, Figure 3C-D). Nevertheless, the loss of teeth had been progressing further and was limited in extent to the interconnected teeth. No tissue samples were taken and examined during the period of tooth resorptions.

Orofacial findings. In addition to previous paediatric findings, a prominent front was evident. However, the patient's facial aspect was inconspicuous in general. On oral examination, the wide tooth gap of the anterior mandible, which resulted from the loss of teeth $32-42$, was noticeable. A lower premolar was missing on both mandibular sides, obviously due to earlier orthodontic extractions (Figure 3BC). The remaining dentition was well maintained, the teeth firmly rested in their sockets and responded adequately to cold stimuli. In the defect area, the mucosa was intact, rosy, and covered the residual bone in a smooth surface. No soft tissue masses were visible or palpable in the defect region.
In the toothless mandibular area, the mucosa firmly attached to the residual bone. There was neither pressure pain nor pathological mobility of the mandible. The tongue was rather voluminous and partly covered the mandibular anterior alveolar ridge when teeth were occluding.

Radiology. A recent orthopantomography (OPG) documented small root tips remaining in the inconspicuous bone in the border area of the bone to the mucosa (Figure 3E). From the previous radiographs, discrete apical root resorptions during orthodontic treatment can be traced on dental films during the $9^{\text {th }}$ to $14^{\text {th }}$ year (Figure 1A-D) and on OPGs (Figure 3). However, the periradicular areas were not radiotranslucent at any time of radiological documentation. At present, the partial loss of the vestibular bone border and the cranial moving of the small tooth remnants show extrusion of the root remnants, three of which are still in situ at the time of the examination (Figure 2 and Figure 3). The periradicular regions are surrounded by bone whose radiopaque trabecular structure extends continuously to the tooth remnants (Figure 2).

Radiological follow-up of orthodontic treatment. The provided radiographs show destruction of the first tooth registered during orthodontic therapy at the age of 14 years. At that time, radiograph provides evidence of orthodontic teeth fixation (Figure 1A). Individual steps of orthodontic therapy can be verified based on the X-ray images presented.

Dental films: The dental films of the mandibular frontal teeth show stages of progressive cervical root resorptions starting from February 2018 and terminating in December 2020 (Figure 1A-D).

Orthopantomogram (OPG): The first OPG (Figure 3A) shows premature loss of all deciduous second molars. There is a lack of space for the permanent premolars. The roots of all anterior teeth are without any pathological findings.

The next OPG (Figure 3B) shows significant space deficiency concerning emergence of both lower second premolars (No. 35, 45, coding of teeth according to the definition of the International Dental Association), as well as slight space deficiency concerning emergence of upper canines (No. 13, 23). There is a lingual arch applied in the mandible to stop further mesial migration (mesial shift) of the molars, as well as to protruding of the anterior mandibular teeth. The anterior roots are still without pathological findings. The maxillary first molars show bands to which a headgear can be attached to distalize the maxillary molars.

The next OPG (5 years later, Figure 3C) presents the dental situation after extraction of 4 premolars (two in each jaw, bilateral) and orthodontic gap closure following tooth extractions. The wisdom teeth are emerging, and the root of the left inferior central incisor (No. 32) is completely resorbed.

About 5 months later (Figure 3D), the right inferior central incisor's root (No. 41) is also resorbed except for the 

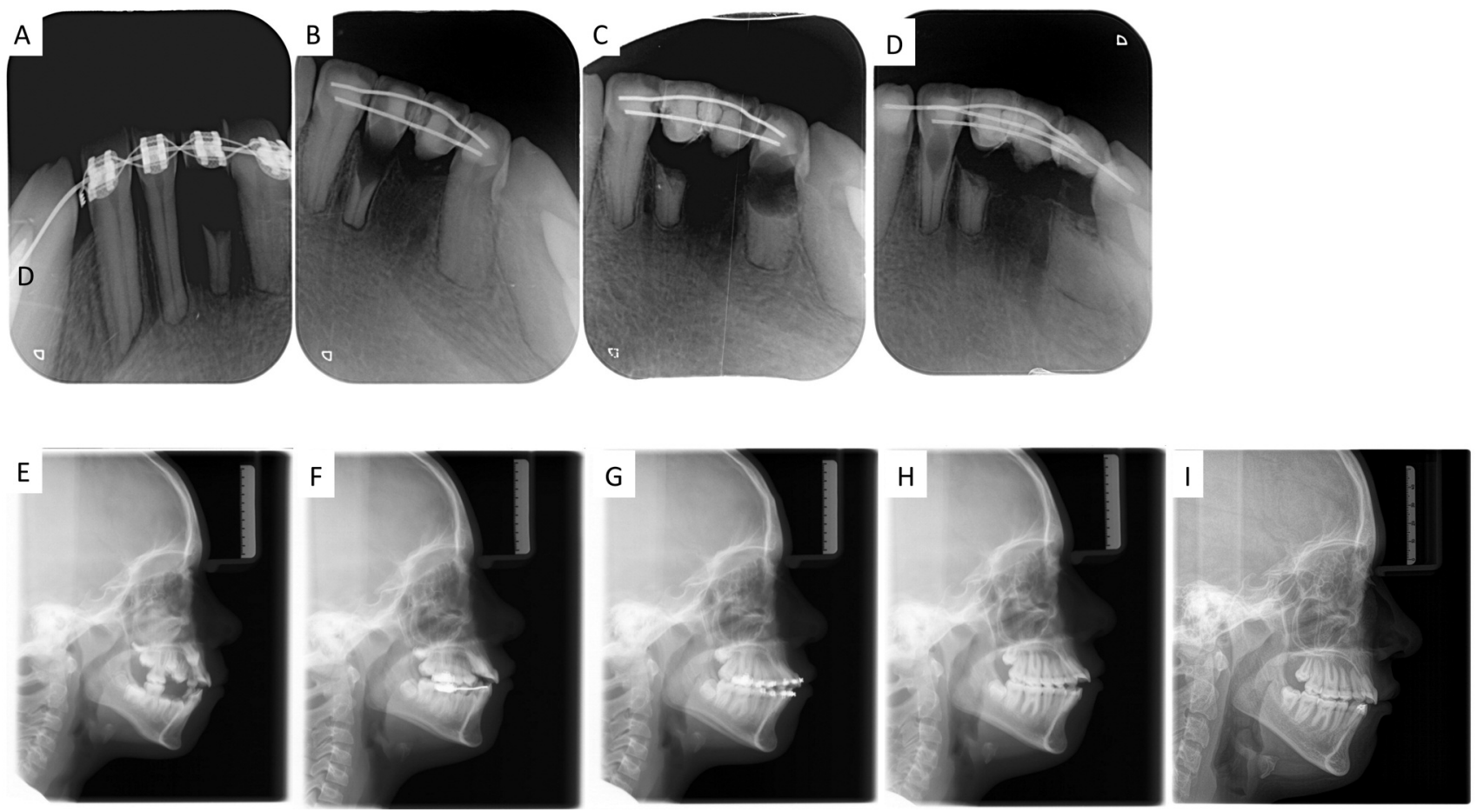

Figure 1. Cervical root resorptions (CRR) of the lower incisors. Figures A-D are single images of the anterior teeth at different stages of tooth destruction. (A) Resorption of the root of tooth 31 (Age: 13 years, 10 months). The resorption starts from the middle third of the tooth. The tooth is already divided into crown and apical third. The crowns of the incisors are provided with brackets and connected to each other by an arch wire. (B) The x-ray image shows the dissolution of the right lower central incisor (No. 41). The destruction of the tooth begins in the middle third of the root. The adjacent bone has a preserved trabecular structure. The alveolar limbus of the tooth extends just to the crown-root interface. The incisors are interconnected with a wire splint (Age: 14 years, 5 months). (C) The figure shows the destruction of tooth 32 . The disease has started in the middle of the tooth (Age: 15 years, 5 month). (D) The figure shows the destruction of the lower right lateral incisor (No. 32). The continuity of root and crown is still preserved. As in the previous tooth destructions, the pulp canal is not visible within the resorption surface of this tooth. The radiographic findings are reminiscent of an internal resorption of the tooth (Age: 16 years, 8 months). However, the two-dimensional radiograph is unsuitable for depicting the vestibular and lingual tooth surfaces. The resorbed root tips of all four incisors with apically preserved alveolar lining in continuity are striking. Figures E-I are cephalograms from the $8^{\text {th }}$ to the 14th year of life (Age E: 8 years, F: 9 years, 6 months; G: 10 years, 6 months; $H: 14$ years, 1 months). The analysis of the cephalograms is given in the text.

root tip. The apical parts of maxillary incisors' roots (No. 12 to 22) appear slightly resorbed considering the extra-long roots of all other maxillary teeth.

The current OPG (Figure 3E) shows resorption of all mandibular anterior teeth with persistent root tips 32,41 , and 42. The maxillary incisors apices show progressive resorption.

Lateral cephalograms. The cephalometric lateral radiographs show skeletal recession of the mandible in sagittal plane, vertically the increased interbase angle [ML - NL angle, i.e., inclination of the mandibular line (ML) to the maxillary line $(\mathrm{NL})]$ and the elongated lower face (Figure 1E-I).

The first radiograph (Figure 1E) shows a molar relation of $1 / 2$ premolar widths (PW) defining class II occlusion of teeth. This dentoalveolar relation is corrected to class I as shown on lateral cephalograms one and two years later (Figure 1F-
G). However, the skeletal situation of the radiographs may have been influenced habitually (mandibular advancing during taking of radiograph). Further four years later (Figure $1 \mathrm{H})$, the molar relation is again $1 / 2 \mathrm{PW}$ class II. Finally, at the time of incisor loss (Figure 1I), the molar relation has deteriorated to a full PW Class II.

The anterior position of teeth shows a sagittal step of 5 $\mathrm{mm}$ in 2012, of $3 \mathrm{~mm}$ in 2013 and 2014, and again $5 \mathrm{~mm}$ in 2016 and 2018, revealing retrusion of anterior teeth with complete relapse to the initial relation at the time of tooth loss. Vertically, radiographs reveal overbite of $-2 \mathrm{~mm}$ in $2012,+2 \mathrm{~mm}$ in 2013 and 2014. In 2014, the radiograph shows complete dentition and severe anterior open bite ( -5 $\mathrm{mm}$ ). Finally, at the time of tooth resorption (2018), the open bite is reduced to $0 \mathrm{~mm}$ after extraction of 4 premolars and retrusion of the frontal teeth. 


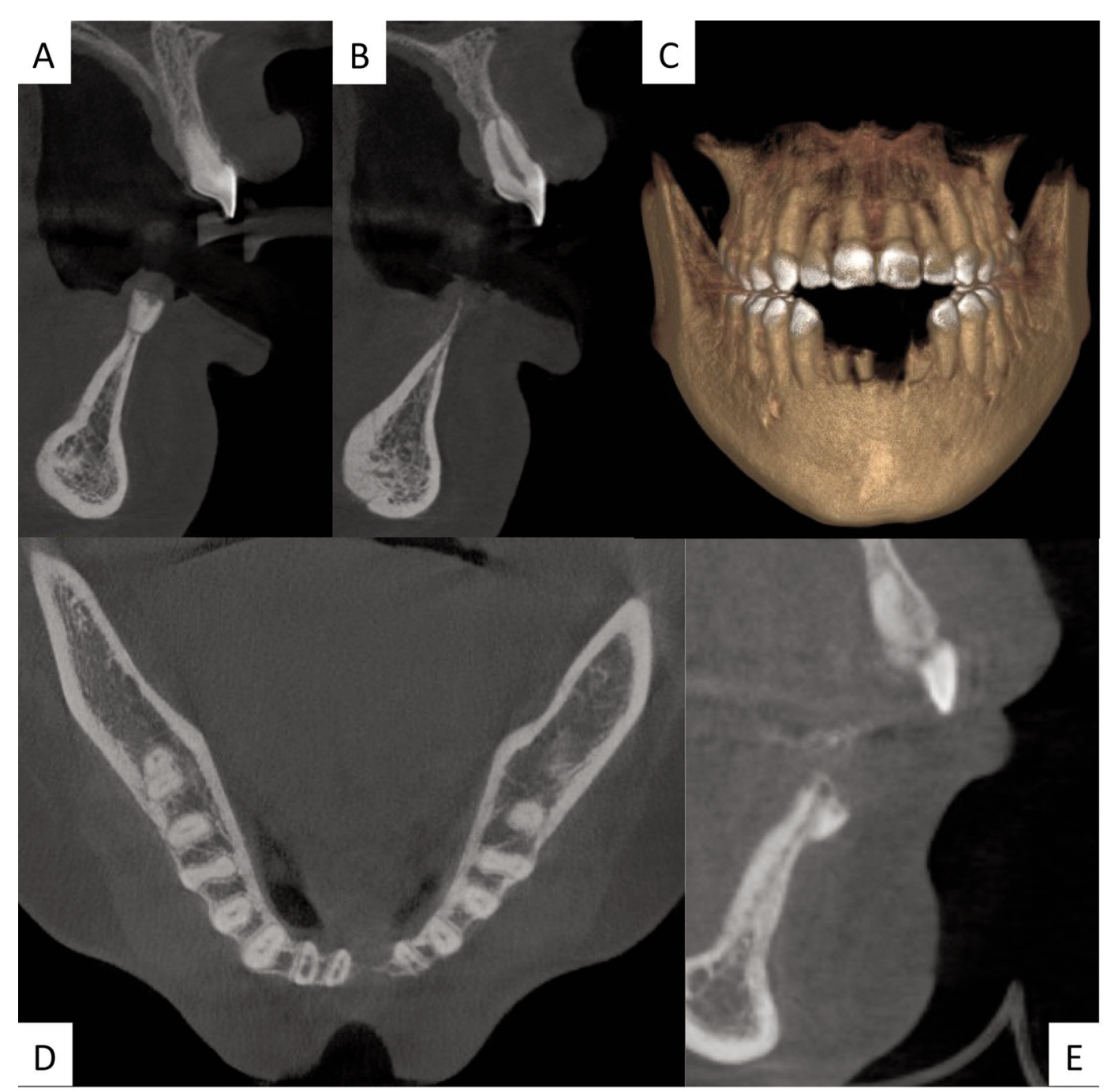

Figure 2. Cone beam computed tomograms (CBCT) after multiple teeth loss of the anterior mandible (cropped images; A, B and E: Sagittal sections; $C: C B C T$ jaws and teeth surface reconstruction; D: Axial section). (A) Regularly structured cancellous anterior mandible with intact cortical layer. The residual tooth root is only apically fixed in the bone. (B) Orally tapering bone at the site of complete tooth loss. (C) The surface reconstruction of the jaws illustrates the width of the tooth gap. Note the shortened roots of the maxillary incisors. (D) Axial representation of the mandible. No periradicular translucencies are shown on the remaining teeth and the dental pulp channels are intact. Note the rounded apex of the maxillary incisor $(A, B, E)$. (E) Extrusion of a residual root of the anterior mandible.

Radiological follow-up of tooth loss. The radiographs of the jaws show the dissolution of the teeth, starting in the middle third of the tooth. Each tooth destruction is associated bilaterally with some loss of the adjacent alveolar bone. However, the temporal sequence of the destruction of the hard substances can only be assumed based on the X-ray findings. At first glance, the radiographic configuration of the dissolution of teeth 41,32 , and 42 is reminiscent of internal root resorption (Figure 1A-D), because the roundish-oval pathologic enlargement of the pulp with corresponding dissolution of the dentin appears to occur within a frame of intact external root. In addition, the dental pulp is no longer detectable on the radiograph in the area of the tooth destruction. However, when evaluating the plain X-ray image, it must be considered that the root surfaces perpendicular to the central beam cannot be assessed in a two-dimensional Xray examination. Therefore, it cannot be ruled out that lateral resorption of the tooth starting in the root surface perpendicular to and initially growing parallel to the central beam of the X-ray was the cause of pulp resorption. Internal resorption of the teeth seen on the radiographs very likely is the late state of tooth destruction during lateral tooth resorption, suggesting a different pathological mechanism only due to the radiological projection. 

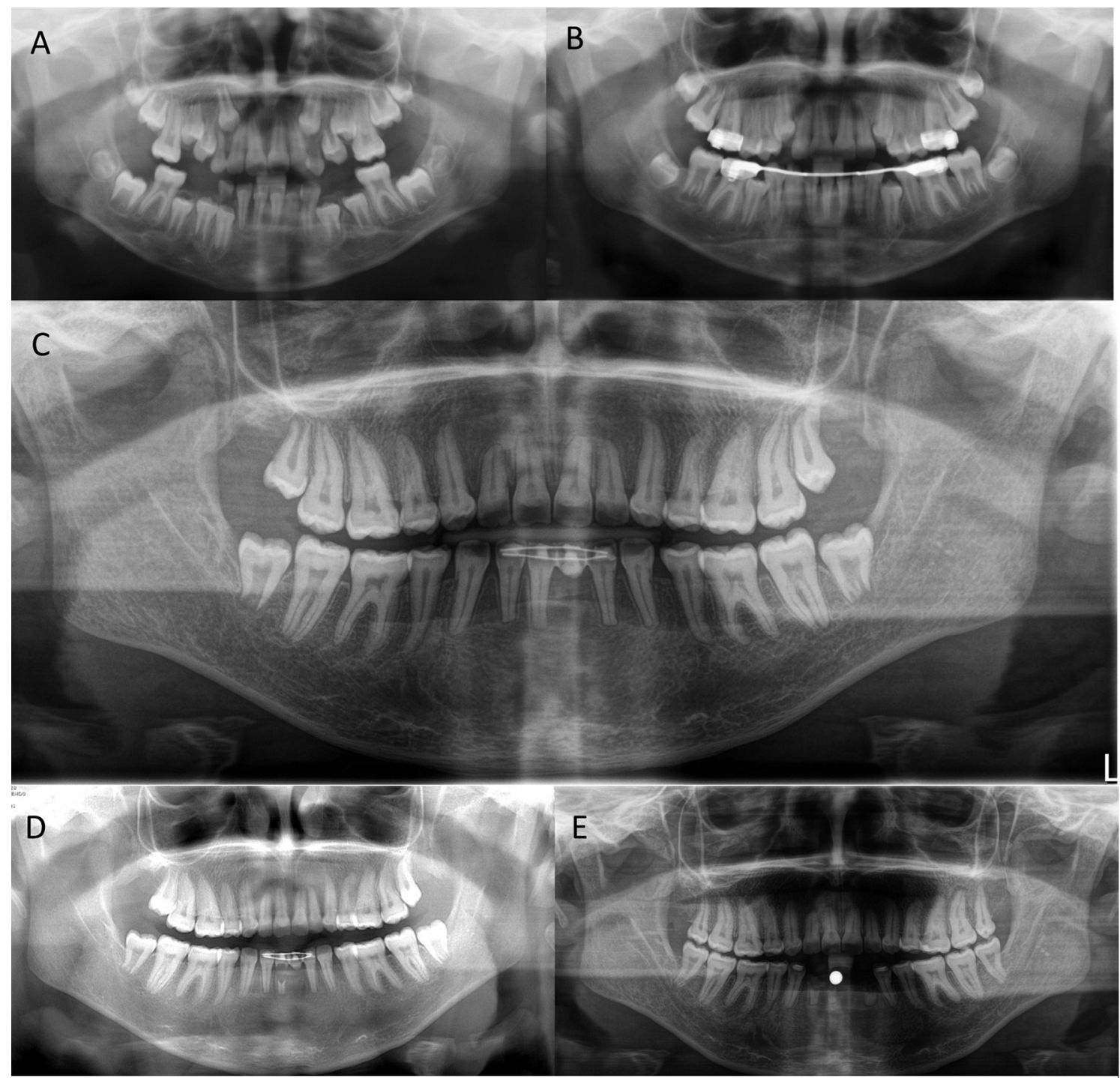

Figure 3. Orthopantomograms $(O P G)$ of the patient with loss of mandibular incisors, taken between the $8^{\text {th }}(A)$ and $17^{\text {th }}(E)$ year of life. (A) Mixed dentition with erupting lateral and already emergent central mandibular incisors (Age: 8 years). (B) Lingual arch inserted in mandible, fully developed roots of lower incisors, lack of space of emergent lower premolars (Age: 9 years, 5 months). (C) Loss of the root of the lower left central incisor. Lower incisors are fixed coronally to each other by arch wire splinting. In this picture, the apices of the lower incisors and canines are somewhat shortened but intact. Likewise, the periodontal boundaries of the incisors' roots appear inconspicuous (Age: 14 years). (D) Five months later, the lower right central incisor is already destroyed. (E) General view after destruction of the lower incisors with measuring body for implant planning (Age: 17 years, 5 months).

All radiological documents confirm the onset of destruction in a single tooth accompanied by dissolution of the adjacent bone. None of the radiographs are suggestive of a primary intraosseous lesion. The origin, extent and course of the tooth destruction are indicative of (invasive) cervical root resorption of the inferior incisors.

The residual bone tapers towards the oral mucosa to form a sharp edge, which is poorly suited for the planned placement of dental implants at the level of the remaining teeth without further treatment, for example with bone substitute material.

\section{Discussion}

This report documents the protracted, sequential loss of teeth in a young patient with NS. The causes of teeth loss had to be evaluated retrospectively, after completion of the destruction phase of the teeth and bone. Retrospectively, the diagnosis can 
only be suspected. The most plausible diagnosis is invasive cervical root resorption (synonymous: invasive lateral tooth resorption) following orthodontic therapy. The entity is rare and well described in dental literature.

The patient's medical history and the X-rays of her orthodontic treatment reveal significant positional changes in sagittal direction of those teeth that were later lost. The orthodontic tooth movements may have been effective for tooth loss even after removal of the appliances, especially if pre-existing antagonizing forces can act on the loosened teeth due to orofacial dysfunctions, such as lip suction and tongue pressure $(25,26)$.

Neither the radiologically documented course of the disease with sequential tooth loss after destruction of the middle sections of the respective tooth, nor the limited damage to the adjacent bone (limbus alveolaris) correspond to the typical radiological patterns of NS-associated CGCL of the jaw $(11-22,27,28)$. However, the presumption of syndrome-associated osseous lesion and tooth loss was crucial for the extended medical diagnosis and identification of NS in the patient and first-degree relatives.

Coincidence of the tooth destruction following orthodontics with the syndrome is likely, in other words, a causal conditioning of the dissolution of teeth and bone by a syndrome-associated neoplasm is unlikely.

Noonan syndrome (NS). NS is a highly variable multisystemic disease characterized by short stature, typical facial dysmorphia, congenital heart defects, cardiomyopathies, and an increased risk of developing tumors in childhood (1). Prevalence of NS among live births is estimated to be $1: 1,000$ to $1: 2,500$ (1).

Etiology of NS. Different genes can cause a disease currently called NS, a RASopathy. About half of cases are caused by mutations in the protein tyrosine phosphatase non-receptor 11 (PTPN11) gene (location: chromosome 12q24.1). About another $15 \%$ of cases shows mutations in the son of sevenless homolog 1 (SOS1) gene (2p22.1). Less commonly, diseasecausing genetic alterations are found in rat fibrosarcoma 1 (RAF1) gene (3p25.2), RAS like without CAAX1 (RIT1) gene (1q22), leucine zipper like transcription regulator 1 (LZTRI) gene (22q11.21), and other genes associated with the rat sarcoma (RAS)/mitogen-activated protein kinase (MAPK) pathway (RAS/MAPK pathway). The presented case shows mutation in a gene rarely causative for NS. It is assumed that the RIT1-associated Noonan phenotype preferentially affects the cardiovascular system $(29,30)$.

Inheritance of NS. Inheritance of NS is autosomal dominant excepting mutations of LZTR1, which can be either dominant or recessive. The clinical spectrum of NS may differ slightly depending on the causative genes, and some phenotypes have been described as "Noonan-like" (e.g., Noonan-like syndrome with juvenile myelomonocytic leukemia, Noonanlike syndrome with loose anagen hair) (1).

Diagnostic procedures in NS. Diagnosis is based on clinical manifestations but can be difficult to achieve because of the highly variable presentation in affected individuals. Molecular genetic testing of causative genes aids in diagnosis and genetic counseling. Mild cases may go undiagnosed and not be clinically noticed until adulthood or after the birth of a more severely affected child (1). In the presented case, the patient's files documented genetic testing of patient, parents, and sister during patient's puberty.

Differential diagnosis of NS. Differential diagnoses include other RASopathies (cardio-facio-cutaneous syndrome, Costello syndrome, neurofibromatosis type 1(NF1)) and Noonan-like syndromes, Baraitser-Winter syndrome, Aarskog syndrome, and Escobar syndrome (1).

NS phenotype in the head and neck region. Characteristic facial features of NS patients are often more pronounced in infancy, e.g., high broad forehead, hypertelorism, downward slanting palpebral fissures, unusual positioning of pinna, deep philtrum, micrognathia, a short neck, occasionally combined with pterygium colli. With age, the face may become triangular, with prominent skin folds (1). However, such findings by no way allow diagnosis of a certain syndrome. Rather, a combination of facial findings justifies a thorough physical investigation of a patient. It must be emphasized that the findings considered characteristic of the syndrome were very mild in this patient. Furthermore, the radiographs frequently reveal dental malposition associated and frontal open bite. Some authors detail orofacial habits associated with open bite in NS patients (25).

CGCL in NS. CGCL is an osseous feature of NS (4, 11-22, 27 , 28). However, CGCL has variable radiographic characteristics irrespective of syndromic or sporadic cause. Diagnosis based solely on radiographs is incomplete. CGCLs are radiolucent uni- or multi-locular lesions of osseous origin, usually well demarcated, occasionally scalloped and expansile. Larger lesions may form asymmetric spaces and cause cortical expansion. In topographic relation to teeth, the most common effect of CGCL on teeth is tooth displacement. Some authors assess tooth resorption a rare finding in CGCL (31). However, the prevalence of tooth resorption in NS is unknown. In clinical studies, resorption of roots in CGCL was recorded in $13.5 \%$ on radiographs and occurred predominantly in large lesions $[\mathrm{n}=89$, small apical lesions $n=8$, root resorption $n=12$, the latter lesion predominantly in unilocular CGCL (6)]. This study included patients with syndromes (NS, NF1, cherubism), but did not differentiate between sporadic and syndrome-associated dissolution of roots. Schematic drawings depicting localization 
and size of CGCL allow interpretation that at least some lesions may have been associated with CRR, but the authors explicitly refer to "root resorption" as a general term (6). Nevertheless, CGCL preferentially resorb affected teeth in an apical to coronal direction and this happens only in some NS cases, e.g., 4/18 (7); 4/23 (8); 6/26 (9). A recent review on features of CGCL $(\mathrm{N}=2270)$ calculated the risk of associated tooth being resorbed due to the lesion to be $22.8 \%$, irrespective of genetic status. However, the type of tooth resorption is not specified and data on tooth resorption were not reported in more than $50 \%$ of evaluated cases (10). In a more recent clinical study on dental and maxillofacial features in 10 patients with NS, a successful orthodontic procedure to correct the open bite was demonstrated in one case (22). Other individual findings include dysmorphic and missing teeth, disturbances of tooth emergence, two cases with odontomas and in one case a radio-translucent lesion of the mandible diagnosed as CGCL. This CGCL caused significant resolution of the mandible at the mandibular angle without damaging the integrity of the adjacent tooth roots.

All the described characteristics of CGCL - both syndrome-associated and sporadic - define a primary osseous lesion, which in individual cases may secondarily infiltrate extraosseous tissues. The sequential osteolysis in the presented case occurs synchronously and in close topographic relation to the dissolution of the diseased tooth. Clinical and radiological course argue against CGCL and in favour of invasive cervical root resorption.

Unusual and noteworthy for the interpretation of the present case is another case of the Lutz et al.'s study (22) that showed multiple teeth having short root apices. However, it is not clear from the documentation whether these are findings with or without prior orthodontic therapy. Nevertheless, several reports on surgical-orthodontic therapy for treatment of malocclusion in NS show favourable results $(32,33)$.

NS and vascular dysfunction. Vascular complications in NS have been reported frequently and rarely also in orthognathic surgery (32). The genetic alterations of the vasculature of NS extend far beyond the clinically prominent cardiac diseases (1). The patient's outpatient diagnostics did not clarify whether changes in the vascular system may have promoted the dentoalveolar disease (34-36).

Tooth resorption and orthodontics. The onset of tooth dissolution during orthodontic therapy in this case is striking. Physical transposition of teeth by orthodontic appliances requires degradation and remodelling of hard tissues, whereby resorptions of tooth roots may occur. Horizontal movement of the teeth may cause apical root resorption. The usually focal resorption of tooth roots exposed to the load of orthodontic tools is a well-known dental finding. Thus, shortening of the longitudinal axis of the tooth is a frequent sequela of orthodontics (37) and noticed in the present case (Figure 1,
Figure 2 and Figure 3). In addition to physical forces of orthodontic therapy, previously unknown genetic factors are also suspected to be influencing this phenomenon (38).

However, (invasive) cervical root resorption (CRR) of teeth differs from apical root resorption by lesion's localization (apical vs. cervical), extension (limited shortening of the apex $v s$. dissolution of the middle third of the root) and consequences to tooth preservation (normally shortened, vital tooth $v s$. extensive destruction of the hard tissues and tooth loss) (39-47). CRR has also been reported several times in orthodontics, is a rare phenomenon and usually affects a single tooth. In the reported case, orthodontic treatment is documented in the radiograph only for the time where the first tooth loss of the mandibular front had become evident (Figure 1A). This radiograph also shows a rounding of mandibular incisors' apices and shortening of their roots prior to the period of tooth resorption. Since that time, no orthodontic instruments that could have been used to induce tooth movement have been documented on the radiographs. The preserved incisor crown was firmly connected to the other incisors with a splint, possibly for aesthetic reasons (Figure 2B). However, the resorption of adjacent tooth is evident on this radiograph. Fixation of inferior incisors was ineffective to prevent further tooth loss, as shown in successive radiographs.

CRR is a dental disease of unknown cause (synonymous: external cervical resorption, invasive root resorption) (39). However, history of trauma or orthodontic treatment are a frequently noted event in affected individuals (40-42, 44-47). Distinguishing CRR from internal resorptive lesions of teeth is difficult to achieve. Tooth destruction with adjacent loss of alveolar bone is an argument to favour CRR (42). Some authors state that an important radiological distinguishing feature between CRR and internal root resorption (IRR) is a continuous boundary of the pulpal wall that is visibly preserved in the radiograph in CRR (48). However, this radiological artifact depends on the stage of tooth destruction and on the imaging technique. In a case of carefully investigated multiple IRRs, the pulp wall visible within the lesion on the native specimen in two-dimensional radiograph could not be visualized on $\mu \mathrm{CT}$ (49). Localization of CRR obviously is multifactorial: CRR was recorded in cleft palate patients only in the maxilla (43).

The literature search for a combination of complications after tooth replacement by dental implants in patients with NS did not yield any results. Recent studies have reported that peripheral giant cell lesions have developed close to implant abutments in individual cases (50). These were sporadic cases. Genetic studies have shown mutations of a gene involved in the control of RAS [Kirsten RAS $(K R A S)]$ in about $50 \%$ of the lesions (50).

\section{Conclusion}

Oral manifestations of NS can provide important clues for diagnosing the underlying disease. The findings must be 
carefully examined. In this case, coincident disease of the teeth and periodontium paved the way to correct syndrome diagnosis. Consideration of other symptoms and findings is often crucial for the classification of local, initially unclear findings to identify a syndrome. Oral findings should be carefully evaluated before suspecting a relationship with a syndrome that is also characterized by dental and jaw findings.

\section{Conflicts of Interest}

The Authors have no conflicts of interest regarding the work presented.

\section{Authors' Contributions}

Evaluation of data, diagnosis of patient, drafting the manuscript, and final approval of the manuscript: REF, HAS.

\section{References}

1 Roberts AE, Allanson JE, Tartaglia M and Gelb BD: Noonan syndrome. Lancet 381(9863): 333-342, 2013. PMID: 23312968. DOI: $10.1016 / \mathrm{S} 0140-6736(12) 61023-X$

2 Cao H, Alrejaye N, Klein OD, Goodwin AF and Oberoi S: A review of craniofacial and dental findings of the RASopathies. Orthod Craniofac Res 20(Suppl 1): 32-38, 2017. PMID: 28643916. DOI: 10.1111/ocr.12144

3 Breilyn MS and Mehta L: Clinical manifestations of Noonan syndrome and related disorders. Pediatr Endocrinol Rev 16(Suppl 2): 428-434, 2019. PMID: 31115194. DOI: 10.17458/per. vol16.2019.bm.clinicalnoonan

4 Flanagan AM and Speight PM: Giant cell lesions of the craniofacial bones. Head Neck Pathol 8(4): 445-453, 2014. PMID: 25409853. DOI: $10.1007 / \mathrm{s} 12105-014-0589-6$

5 Gomes CC, Diniz MG, Bastos VC, Bernardes VF and Gomez RS: Making sense of giant cell lesions of the jaws (GCLJ): lessons learned from next-generation sequencing. J Pathol 250(2): 126133, 2020. PMID: 31705763. DOI: 10.1002/path.5365

6 De Lange J and Van den Akker HP: Clinical and radiological features of central giant-cell lesions of the jaw. Oral Surg Oral Med Oral Pathol Oral Radiol Endod 99(4): 464-470, 2005. PMID: 15772595. DOI: 10.1016/j.tripleo.2004.11.015

7 Kaffe I, Ardekian L, Taicher S, Littner MM and Buchner A: Radiologic features of central giant cell granuloma of the jaws. Oral Surg Oral Med Oral Pathol Oral Radiol Endod 81(6): 720-726, 1996. PMID: 8784905. DOI: 10.1016/s1079-2104(96)80079-5

8 Kaplan I, Manor I, Yahalom R and Hirshberg A: Central giant cell granuloma associated with central ossifying fibroma of the jaws: a clinicopathologic study. Oral Surg Oral Med Oral Pathol Oral Radiol Endod 103(4): e35-e41, 2007. PMID: 17395058. DOI: $10.1016 /$ j.tripleo.2006.03.017

9 Kruse-Lösler B, Diallo R, Gaertner C, Mischke KL, Joos U and Kleinheinz J: Central giant cell granuloma of the jaws: a clinical, radiologic, and histopathologic study of 26 cases. Oral Surg Oral Med Oral Pathol Oral Radiol Endod 101(3): 346-354, 2006. PMID: 16504869. DOI: 10.1016/j.tripleo.2005.02.060

10 Chrcanovic BR, Gomes CC and Gomez RS: Central giant cell lesion of the jaws: An updated analysis of 2270 cases reported in the literature. J Oral Pathol Med 47(8): 731-739, 2018. PMID: 29751369. DOI: $10.1111 /$ jop. 12730

11 Eyselbergs M, Vanhoenacker F, Hintjens J, Dom M, Devriendt $\mathrm{K}$ and Van Dijck H: Unilateral giant cell lesion of the jaw in Noonan syndrome. JBR-BTR 97(2): 90-93, 2014. PMID: 25073238. DOI: $10.5334 /$ jbr-btr.20

12 van den Berg H, Schreuder WH, Jongmans M, van Bommel-Slee $\mathrm{D}$, Witsenburg B and de Lange J: Multiple giant cell lesions in a patient with Noonan syndrome with multiple lentigines. Eur J Med Genet 59(8): 425-428, 2016. PMID: 27238887. DOI: 10.1016/j.ejmg.2016.05.013

13 Sinnott BP and Patel M: Giant cell lesion of the jaw as a presenting feature of Noonan syndrome. BMJ Case Rep 2018: bcr2017224115, 2018. PMID: 29848529. DOI: 10.1136/bcr-2017-224115

14 Betts NJ, Stewart JC, Fonseca RJ and Scott RF: Multiple central giant cell lesions with a Noonan-like phenotype. Oral Surg Oral Med Oral Pathol 76(5): 601-607, 1993. PMID: 8247501. DOI: 10.1016/0030-4220(93)90069-g

15 Sarkozy A, Obregon MG, Conti E, Esposito G, Mingarelli R, Pizzuti A and Dallapiccola B: A novel PTPN11 gene mutation bridges Noonan syndrome, multiple lentigines/LEOPARD syndrome and Noonan-like/multiple giant cell lesion syndrome. Eur J Hum Genet 12(12): 1069-1072, 2004. PMID: 15470362. DOI: $10.1038 /$ sj.ejhg.5201290

16 Edwards PC, Fox J, Fantasia JE, Goldberg J and Kelsch RD: Bilateral central giant cell granulomas of the mandible in an 8year-old girl with Noonan syndrome (Noonan-like/multiple giant cell lesion syndrome). Oral Surg Oral Med Oral Pathol Oral Radiol Endod 99(3): 334-340, 2005. PMID: 15716842. DOI: 10.1016/j.tripleo.2004.08.021

17 Hanna N, Parfait B, Talaat IM, Vidaud M and Elsedfy HH: SOS1: a new player in the Noonan-like/multiple giant cell lesion syndrome. Clin Genet 75(6): 568-571, 2009. PMID: 19438935. DOI: 10.1111/j.1399-0004.2009.01149.x

18 Neumann TE, Allanson J, Kavamura I, Kerr B, Neri G, Noonan J, Cordeddu V, Gibson K, Tzschach A, Krüger G, Hoeltzenbein M, Goecke TO, Kehl HG, Albrecht B, Luczak K, Sasiadek MM, Musante L, Laurie R, Peters H, Tartaglia M, Zenker M and Kalscheuer V: Multiple giant cell lesions in patients with Noonan syndrome and cardio-facio-cutaneous syndrome. Eur J Hum Genet 17(4): 420-425, 2009. PMID: 18854871. DOI: 10.1038/ejhg.2008.188

19 Bufalino A, Carrera M, Carlos R and Coletta RD: Giant cell lesions in noonan syndrome: case report and review of the literature. Head Neck Pathol 4(2): 174-177, 2010. PMID: 20383758. DOI: 10.1007/s12105-010-0178-2

20 Moskovszky L, Idowu B, Taylor R, Mertens F, Athanasou N and Flanagan A: Analysis of giant cell tumour of bone cells for Noonan syndrome/cherubism-related mutations. J Oral Pathol Med 42(1): 95-98, 2013. PMID: 22725657. DOI: 10.1111/j.1600-0714.2012. 01194.x

21 Ferriero K, Shah B, Yan Y, Khatri S, Caccamese J, Napoli JA, Bober MB and Crane JL: Case report: Safety and efficacy of denosumab in four children with Noonan syndrome with multiple giant cell lesions of the jaw. Front Pediatr 8: 515, 2020. PMID: 33042901. DOI: 10.3389/fped.2020.00515

22 Lutz JC, Nicot R, Schlund M, Schaefer E, Bornert F, Fioretti F and Ferri J: Dental and maxillofacial features of Noonan Syndrome: Case series of ten patients. J Craniomaxillofac Surg 48(3): 242-250, 2020. PMID: 32113883. DOI: 10.1016/j.jcms.2020.01.011 
23 Olson NJ, Addante RR, de Abreu FB and Memoli VA: Centra xanthoma of the jaw in association with Noonan syndrome. Hum Pathol 82: 202-205, 2018. PMID: 29727697. DOI: 10.1016/ j.humpath.2018.04.020

24 Toureno L and Park JH: Atypical orofacial conditions in Noonan syndrome: a case report. J Clin Pediatr Dent 36(2): 197-202, 2011. PMID: 22524084. DOI: 10.17796/jcpd.36.2.81074271088334h2

25 Ierardo G, Luzzi V, Panetta F, Sfasciotti GL and Polimeni A: Noonan syndrome: A case report. Eur J Paediatr Dent 11(2): $97-$ 100, 2010. PMID: 20635845

26 Fonteles CS, de Miranda Mota AC, Lima RA, Borges PC and da Silveira A: Conservative management of severe open bite and feeding difficulties in patient with noonan syndrome. Cleft Palate Craniofac J 50(2): 242-248, 2013. PMID: 22849635 DOI: $10.1597 / 11-214$

27 Bitton N, Alexander S, Ruggiero S, Parameswaran A, Russo A and Ferguson F: Case report: Noonan-like multiple central giant cell granuloma syndrome. Pediatr Dent 34(5): 144-147, 2012 PMID: 23211900

28 Wolvius EB, de Lange J, Smeets EE, van der Wal KG and van den Akker HP: Noonan-like/multiple giant cell lesion syndrome: report of a case and review of the literature. J Oral Maxillofac Surg 64(8): 1289-1292, 2006. PMID: 16860226. DOI: 10.1016/j.joms.2006.04.025

29 Kouz K, Lissewski C, Spranger S, Mitter D, Riess A, LopezGonzalez V, Lüttgen S, Aydin H, von Deimling F, Evers C, Hahn A, Hempel M, Issa U, Kahlert AK, Lieb A, Villavicencio-Lorini P, Ballesta-Martinez MJ, Nampoothiri S, Ovens-Raeder A, Puchmajerová A, Satanovskij R, Seidel H, Unkelbach S, Zabel B, Kutsche $\mathrm{K}$ and Zenker M: Genotype and phenotype in patients with Noonan syndrome and a RIT1 mutation. Genet Med 18(12): 1226-1234, 2016. PMID: 27101134. DOI: 10.1038/gim.2016.32

30 Yaoita M, Niihori T, Mizuno S, Okamoto N, Hayashi S, Watanabe A, Yokozawa M, Suzumura H, Nakahara A, Nakano Y, Hokosaki T, Ohmori A, Sawada H, Migita O, Mima A, Lapunzina P, Santos-Simarro F, García-Miñaúr S, Ogata T, Kawame H, Kurosawa K, Ohashi H, Inoue S, Matsubara Y, Kure $\mathrm{S}$ and Aoki Y: Spectrum of mutations and genotype-phenotype analysis in Noonan syndrome patients with RIT1 mutations. Hum Genet 135(2): 209-222, 2016. PMID: 26714497. DOI: $10.1007 /$ s00439-015-1627-5

31 Gupta M, Kaste SC and Hopkins KP: Radiologic appearance of primary jaw lesions in children. Pediatr Radiol 32(3): 153-168, 2002. PMID: 12164347. DOI: 10.1007/s00247-001-0633-z

32 Sugar AW, Ezsias A, Bloom AL and Morcos WE: Orthognathic surgery in a patient with Noonan's syndrome. J Oral Maxillofac Surg 52(4): 421-425, 1994. PMID: 8133379. DOI: 10.1016/02782391(94)90454-5

33 Kawakami M, Yamamoto K, Shimomura $T$ and Kirita T: Surgical orthodontic treatment for open bite in Noonan syndrome patient: a case report. Cleft Palate Craniofac J 53(2): 253-258, 2016. PMID: 25575339. DOI: 10.1597/14-196

34 Witt DR, McGillivray BC, Allanson JE, Hughes HE, Hathaway WE, Zipursky A and Hall JG: Bleeding diathesis in Noonan syndrome: a common association. Am J Med Genet 31(2): 305317, 1988. PMID: 3232698. DOI: 10.1002/ajmg.1320310208

35 Artoni A, Selicorni A, Passamonti SM, Lecchi A, Bucciarelli P, Cerutti M, Cianci P, Gianniello F and Martinelli I: Hemostatic abnormalities in Noonan syndrome. Pediatrics 133(5): e1299e1304, 2014. PMID: 24753526. DOI: 10.1542/peds.2013-3251
36 Nugent DJ, Romano AA, Sabharwal S and Cooper DL: Evaluation of bleeding disorders in patients with Noonan syndrome: a systematic review. J Blood Med 9: 185-192, 2018. PMID: 30464668. DOI: 10.2147/JBM.S164474

37 Topkara A: External apical root resorption caused by orthodontic treatment: a review of the literature. Eur J Paediatr Dent 12(3): 163-166, 2011. PMID: 22077683.

38 Nieto-Nieto N, Solano JE and Yañez-Vico R: External apical root resorption concurrent with orthodontic forces: the genetic influence. Acta Odontol Scand 75(4): 280-287, 2017. PMID: 28358285. DOI: 10.1080/00016357.2017.1294260

39 Heithersay GS: Invasive cervical resorption: an analysis of potential predisposing factors. Quintessence Int 30(2): 83-95, 1999. PMID: 10356560.

40 Luso S and Luder HU: Resorption pattern and radiographic diagnosis of invasive cervical resorption. A correlative microCT, scanning electron and light microscopic evaluation of a case series. Schweiz Monatsschr Zahnmed 122(10): 914-930, 2012. PMID: 23097140.

41 Darcey J and Qualtrough A: Resorption: part 1. Pathology, classification and aetiology. Br Dent J 214(9): 439-451, 2013. PMID: 23660900. DOI: 10.1038/sj.bdj.2013.431

42 Darcey J and Qualtrough A: Resorption: part 2. Diagnosis and management. Br Dent J 214(10): 493-509, 2013. PMID: 23703177. DOI: $10.1038 /$ sj.bdj.2013.482

43 O'Mahony A, McNamara C, Ireland A, Sandy J and Puryer J: Invasive cervical resorption and the oro-facial cleft patient: a review and case series. Br Dent J 222(9): 677-681, 2017. PMID: 28496230. DOI: 10.1038/sj.bdj.2017.405

44 Shemesh A, Levin A, Ben Itzhak J, Brosh Y, Braverman E, Batashvili $\mathrm{G}$ and Solomonov M: External invasive resorption: Possible coexisting factors and demographic and clinical characteristics. Aust Endod J 45(2): 141-145, 2019. PMID: 30129090. DOI: 10.1111/aej.12292

45 Brito GM, Campos PSF, Mariz ACR, Simões D and Machado AW: Invasive cervical resorption of central incisor during orthodontic treatment. Dental Press J Orthod 25(6): 49-58, 2020. PMID: 33503125. DOI: 10.1590/2177-6709.25.6.049-058.oar

46 Rotondi O, Waldon P and Kim SG: The disease process, diagnosis and treatment of invasive cervical resorption: a review. Dent J (Basel) 8(3): 64, 2020. PMID: 32630223. DOI: 10.3390/dj8030064

47 Galler KM, Grätz EM, Widbiller M, Buchalla W and Knüttel H: Pathophysiological mechanisms of root resorption after dental trauma: a systematic scoping review. BMC Oral Health 21(1): 163, 2021. PMID: 33771147. DOI: 10.1186/s12903-021-01510-6

48 Lübbers HT and Dula K (eds.).: Digitale Volumentomographie. Berlin, Springer, pp. 120-131, 2021.

49 Koehne T, Zustin J, Amling M and Friedrich RE: Radiological and histopathological features of internal tooth resorption. In Vivo 34(4): 1875-1882, 2020. PMID: 32606158. DOI: 10.21873/invivo.11983

50 Martins-Chaves RR, Guimarães LM, Pereira TDSF, Pereira NB, Chrcanovic BR, Fonseca FP, Lafuente-Ibáñez de Mendoza I, Aguirre-Urizar JM, Gomes CC and Gomez RS: KRAS mutations in implant-associated peripheral giant cell granuloma. Oral Dis 26(2): 334-340, 2020. PMID: 31758745. DOI: 10.1111/odi.13241

Received November 25, 2021

Revised December 12, 2021

Accepted December 13, 2021 